\title{
Approaches for the identification of genetic modifiers of nutrient dependent phenotypes: examples from folate
}

\author{
John W. R. Zinck' ${ }^{1}$ and Amanda J. MacFarlane ${ }^{2 *}$ \\ 1 Science Integration Division, Public Health Agency of Canada, Ottawa, ON, Canada \\ ${ }^{2}$ Nutrition Research Division, Health Canada, Ottawa, ON, Canada
}

\section{Edited by:}

Suresh T. Mathews, Auburn

University, USA

Reviewed by:

Zdenka Pausova, The Hospital for Sick Children, Canada

Tony Merriman, University of Otago,

New Zealand

\section{*Correspondence:}

Amanda J. MacFarlane, Nutrition

Research Division, Health Canada,

251 Sir Frederick Banting Drive,

Ottawa, ON K1A OK9, Canada

e-mail: amanda.macfarlane@

hc-sc.gc.ca
By combining the sciences of nutrition, bioinformatics, genomics, population genetics, and epidemiology, nutrigenomics is improving our understanding of how diet and nutrient intake can interact with or modify gene expression and disease risk. In this review, we explore various approaches to examine gene-nutrient interactions and the modifying role of nutrient consumption, as they relate to nutrient status and disease risk in human populations. Two common approaches include the use of SNPs in candidate genes to identify their association with nutritional status or disease outcomes, or genome-wide association studies to identify genetic polymorphisms associated with a given phenotype. Here, we examine the results of various gene-nutrient interaction studies, the association of genetic polymorphisms with disease expression, and the identification of nutritional factors that modify gene-dependent disease phenotypes. We have focused on specific examples from investigations of the interactions of folate, B-vitamin consumption, and polymorphisms in the genes of B-vitamin dependent enzymes and their association with disease risk, followed by an examination of the strengths and limitations of the methods employed. We also present suggestions for future studies, including an approach from an on-going large scale study, to examine the interaction of nutrient intake and genotypic variation and their impact on nutritional status.

Keywords: folate metabolism, folate, folic acid, functional genomics, candidate gene, genome-wide association studies

\section{APPLICATION OF GENOMICS TO ADDRESS PUBLIC HEALTH}

Specific sub-populations may be genetically pre-disposed to high or low status for specific nutrients. New high-throughput sequencing and bioinformatics tools for genetic analysis have opened the door to performing detailed analyses of the interrelationships among dietary intake, nutritional status, and genetic polymorphisms. Data from these studies may in turn be used to inform nutrition policies to maximize public health benefits. For example, we are currently identifying single nucleotide polymorphisms (SNPs) that predict an individual's response to folic acid intake in the Canadian population using samples from the Canadian Health Measures Survey cycle 1 (1). In this review, we explore various approaches to examine gene-nutrient interactions and the effect of nutrient consumption on gene expression and function as they relate to disease risk in human populations. We present specific examples from investigations of the interactions of folate and B-vitamin consumption and polymorphisms in the genes of B-vitamin dependent enzymes and their association with disease risk.

\section{GENE-ENVIRONMENT INTERACTION}

Since the advent of DNA sequencing, numerous genetic polymorphisms have been identified that are associated with human diseases including developmental anomalies, diabetes, cardiovascular disease, and cancer $(2,3)$. SNPs can play an integral role in phenotypic plasticity and contribute to much of the genetic variability observed in phenotypes dependent on gene-environment interactions (4). Although SNPs have been associated with chronic diseases or disorders, in general, a single SNP or group of SNPs (haplotype) is rarely by itself causal (5). Put simply, SNPs are often necessary, but not sufficient, for the development of a given disease.

The majority of chronic diseases are multifactorial and depend on gene-environment interactions $[(5,6)$; Figure 1]. The influence of environmental factors alters the phenotypic expression of a genotype. In the context of disease, these interactions may result in increased susceptibility or resistance depending on both the genotype and environmental exposure. Environmental factors include any non-genetic contribution to a phenotype, which could directly influence the output of a genetic pathway to prevent, initiate, aggravate, or mitigate a pathological response. These can be under an individual's control, such as behavioral or nutritional factors, or they may be beyond an individual's control, such as climate change or unintended exposure to toxins (7).

The outcome of gene-environment interactions can cause a change in genotype ranking (genotypic advantage changes in different environments), a change in scale of phenotypic expression, or a combination of both. Various experimental models of geneenvironmental interaction have been developed to account for ways in which genetic effects can be modified by environmental exposures, taking into account the number of exposures, the level of exposure, the timing of exposure, and the model on which the genetic effects are based $(8,9)$. For example, the most basic 


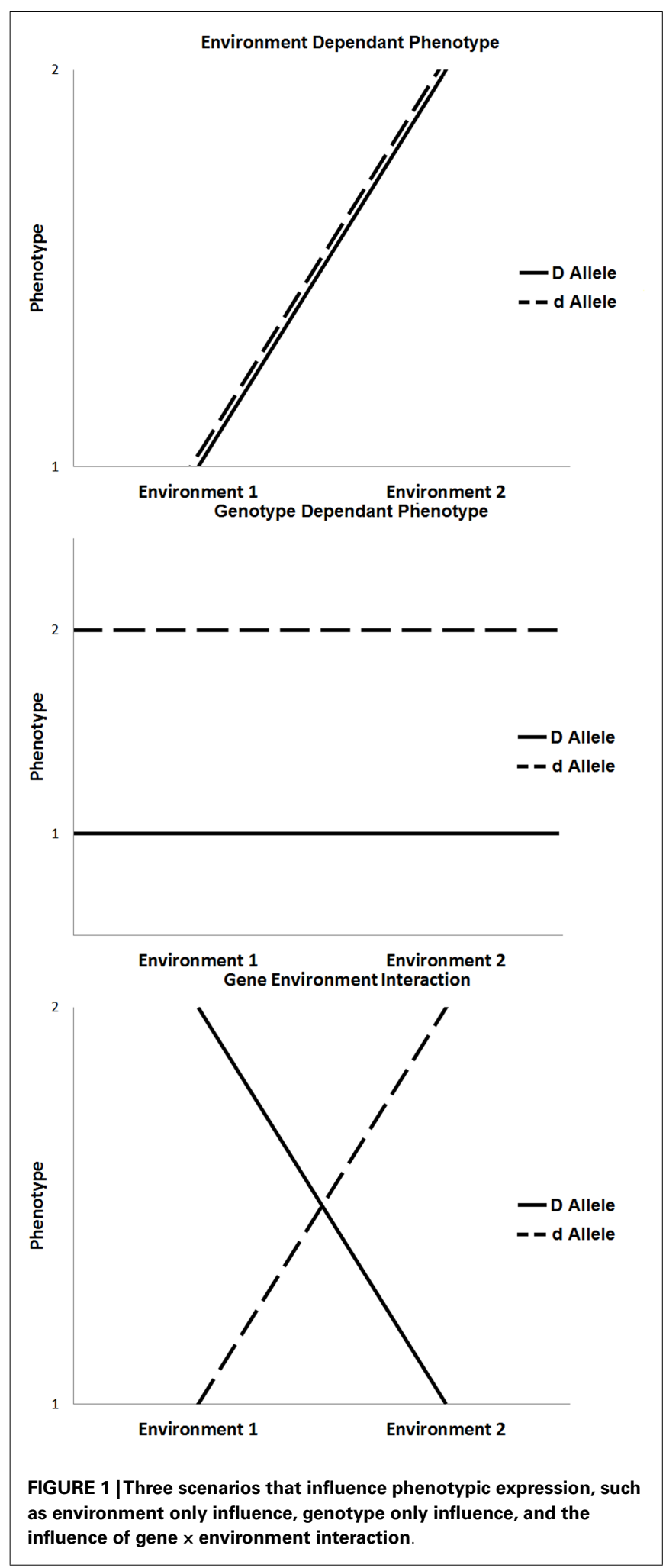

gene-environment interactions include a single environmental factor that alters the expression of a single gene to influence phenotype. In the absence of one or the other, the disease will not occur. More commonly, the expression of a disease phenotype, such as diabetes or cardiovascular disease, is dependent on multiple genes (gene-gene interactions), and single or multiple environmental exposures. In these more complex conditions, any given individual gene or environmental factor is a minor contributor to disease expression; rather, it is the combined effect of multiple genes modified by specific environmental triggers that, when combined, result in disease.

It must be mentioned that one mechanism by which environmental factors can influence gene expression is through epigenetics. Epigenetics is defined as a change in gene expression in the absence of a change to the DNA sequence (10). Epigenetic regulation of gene expression can occur by DNA methylation, methylation or other post-translational modifications of histones, or the activation of microRNAs. In addition, recent studies have revealed that epigenetic variation can interact with genetic variation in the expression of a disease phenotype (11). The concept of epigenetic gene regulation is pertinent in the context of folate metabolism since folate status influences cellular methylation capacity (Figure 2; see also section: Case in point: Nutrigenomic approaches in the study of folate-related pathologies). However, for succinctness, we will limit the scope of our discussion to the interaction between environmental factors and genetic variants.

\section{NUTRIENT DEPENDANT GENETIC ASSOCIATIONS}

Nutrients represent a large, varied, and ubiquitous group of environmental factors involved in gene-environment interactions. The study of gene-nutrient interactions has begun to identify the underlying roles of specific nutrients in disease and developmental disorders. By understanding the mechanisms underlying genenutrient interactions, the nutrition of both individuals and populations may be tailored to reduce the burden of chronic disease. These studies are often based on observed associations between the intake and status of a nutrient with risk for a disease. These associations are often initially observed in case-control, cohort, or longitudinal studies, as well as in animal models. Though, these studies are unable to pinpoint the underlying genetic factors contributing to phenotype expression, they link specific nutrients to a particular disease and provide the foundation on which hypothesis driven experiments can be developed. For example, these types of studies have demonstrated an association between higher serum levels of Vitamin A and reduced risk of lung cancer (12), nutrition in early development and later cognitive development (13), and low maternal folate status and increased neural tube defect (NTD) risk (14).

Two approaches to study how nutrients interact with genes to influence phenotype have been widely applied. The first is the candidate gene approach, which examines the relationship between SNPs in candidate genes (usually nutrient-related genes) and disease risk. The second, GWAS, surveys genetic polymorphisms in a genome-wide fashion to assess their association with disease risk $(15,16)$. Finally, the modifying effect of nutrient intake on the associations between genetic polymorphisms and disease phenotype, or its effect on gene expression in disease can also be examined. With the increasing speed and accuracy of whole genome sequencing, the ability to identify, and characterize these interactions has increased dramatically. 


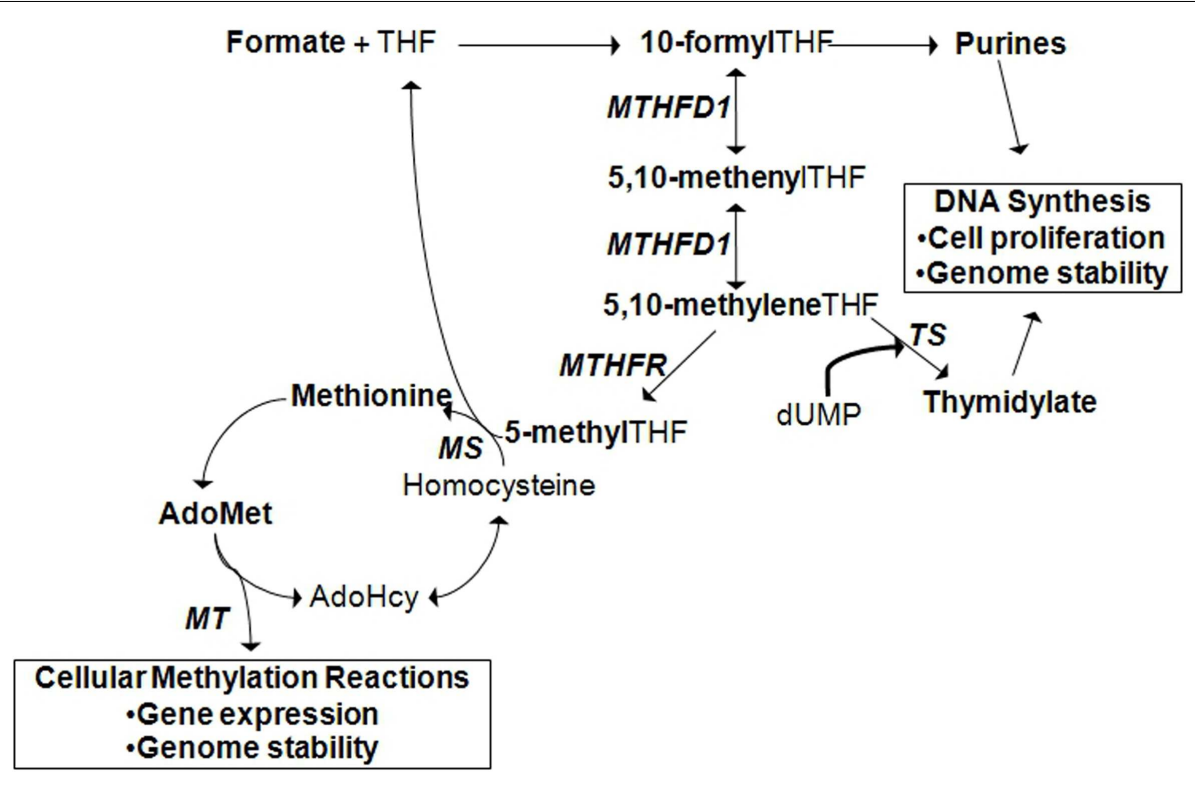

FIGURE 2 | Cytoplasmic folate-mediated one-carbon metabolism is required for de novo purine, thymidylate, and methionine synthesis Cellular methylation potential is dependent on the production of $S$-adenoyslmethionine (AdoMet), the major methyl donor in the cell. Methionine is generated when homocysteine is remethylated. A methyl group can be transferred from 5-methyltetrahydrofolate (THF) by methionine synthase (MS). 5-methylTHF is produced by methylene THF reductase (MTHFR) from the folate metabolic pathway. In the liver and kidney, homocysteine can also be remethylated by betaine:homocysteine methyltransferase (BHMT), a reaction that depends on choline-derived betaine as the methyl donor (not shown). Methionine is converted to AdoMet from which methyltransferases (MT) transfer methyl groups to acceptor molecules. Acceptor molecules include DNA, RNA, histones and other proteins, and other small molecules. The reaction produces $S$-adenosylhomocysteine (AdoHcy) that can be converted to homocysteine. TS, thymidylate synthase; MTHFD1, methylene THF dehydrogenase 1.

\section{FUNCTIONAL GENOMICS FOR NUTRIGENOMICS}

With the development of high-throughput, genomic sequencing technologies, it is feasible to examine links among nutrition, genetics, and phenotype. The majority of nutrigenomic studies have used either a candidate gene or genome-wide association study (GWAS) approach to examine the interrelationship among SNPs or other genetic polymorphisms, nutrient intake, nutrient status, and disease (Table 1).

Candidate gene association studies are preferred when the functional relationship of the target genes with an outcome is known $(17,18)$. The reliance on sometimes limited a priori information and the inability to consider all causative genes for a given trait may hinder the scope of candidate gene studies (1820). New sequencing techniques with faster analysis times are addressing this criticism, in part, by providing a means to economically examine many genetic variants within a candidate gene and expanded sets of candidate genes quickly. Unlike candidate gene studies, GWAS require no prior knowledge of a gene's functional relationship to a given nutrient. In a GWAS, a suite of genetic markers, commonly SNPs, is screened to determine if the frequency of allele variants is significantly different between the case and control groups (21). Of the many advantages of GWAS, the ability to compare SNP allele frequency with quantitative environmental and phenotypic data may be the most important.

Finding which loci in a suite of 100,000 (or more) markers have a significant association with a phenotype presents a difficult statistical problem, similar to finding a needle in a haystack. The statistical power of a GWAS is a function of sample size, effect size, causal allele frequency, and marker allele frequency and its correlation with causal variants. When examining multiple associations, GWASs can be fundamentally underpowered when the association is of modest effect (22). Although the action of multiple factors (genetic or non-genetic), incomplete penetrance, and modest effects reduce analytical power, proper study design, with subjectively selected (large) population sizes, can overcome these limitations (23). However, even in cases with adequate sample size, GWAS have a high potential for false-positive results because of the massive number of markers and statistical tests applied (24). The risk of false positives can be avoided through proper quality control and study design, including using appropriate analytical methods to correct for multiple testing [e.g., Bonferroni corrected $p$-value, false discovery rate, permutation testing, BitForce (25); network-assisted investigation (26); high-dimensional vectors (27)].

The GWAS approach has evolved with new sequencing and computational technology, and now includes random SNP array selections, SNP functional predictions, and exomic SNP analyses that theoretically cover only coding regions of the genome. In these approaches, tag SNPs, a single-marker in a region of high linkagedisequilibrium that can be used to represent the allele frequencies of a group of SNPs, are popular as they dramatically reduce the time and costs associated with examining suites of genetic markers without losing resolution (28). 
Table 1 | A comparison of two major methods used to conduct gene association studies, candidate gene studies, and genome-wide association studies.

\begin{tabular}{|c|c|}
\hline \multicolumn{2}{|c|}{ GENIC ASSOCIATION APPROACH } \\
\hline \multicolumn{2}{|c|}{ Candidate gene studies } \\
\hline \multirow[t]{4}{*}{ Methodology } & Examine associations between genetic polymorphisms and environmental interactions within pre-specified genes of interest \\
\hline & Hypothesis driven, case-control for binary outcomes or single cohort for continuous associations \\
\hline & Requires a priori knowledge of functional relationship between genes and target traits \\
\hline & Increasingly, relationship information is available in online databases \\
\hline
\end{tabular}

Limitations Reliance on existing information may limit scope of examined causative genes

Initial costs associated with identifying target genes and their function can be high if not previously published

Genome-wide association studies (GWAS)

Methodology Examines many (tens or hundreds of thousands) of genetic variants

Contrast two large groups of individuals using case vs. control or a continuous outcome to determine if allelic patterns are significantly associated with a trait of interest

Requires no prior knowledge of relationship between gene function and phenotypic traits

Limitations Requires rigorous quality control to limit false-positive results caused by multiple pairwise comparisons

Large dataset size, lack of functional model testing and confounding biological and environmental factors that are not, or cannot be considered can lead to erroneous associations

Common genetic variants used for some GWAS may not play a role in explaining the heritable variation of common disease

\section{CASE IN POINT: NUTRIGENOMIC APPROACHES IN THE STUDY OF FOLATE-RELATED PATHOLOGIES}

Folate is an essential water-soluble B-vitamin that is required for metabolic one-carbon transfers in the de novo synthesis of purines, thymidylate, and methionine [Figure 2; (29)]. As such, adequate folate consumption is essential for the synthesis, stability, and repair of DNA (29). In conditions of folate deficiency, uracil can be incorporated into DNA in the absence of thymidylate, which can lead to DNA strand breakage and reduced DNA repair. Reduced purine synthesis results in reduced cell proliferation, cell stasis, and death. Folate deficiency also results in increased homocysteine production, a one-carbon metabolism by-product related to cardiovascular disease and other pathologies, due to reduced methionine synthesis (30-32). Reduced methionine synthesis limits the availability of $S$-adenosylmethionine for cellular methylation reactions. Folate deficiency, resulting from inadequate intake or genetic polymorphisms in folate-dependent genes, is associated with increased risk for NTDs, cancer, cardiovascular diseases, and other chronic diseases.

Folate-dependent one-carbon metabolism and homeostasis requires a number of transporters, enzymes, and other nutrient co-factors. Nearly all folate-related genetic studies have used candidate gene or GWAS approaches to identify genetic markers associated with a folate-dependent disease or for the identification of associations among nutrient intake, folate-related genes, and functional outcomes. Screening of more than 1500 SNPs identified in folate and other B-vitamin metabolic pathways has revealed $\sim 150$ SNPs with significant associations with pathological endpoints $(33,34)$. Commonly, studies have either examined the relationship between one or a few genes and nutrient status and/or disease. Others have performed large GWAS analyses to identify the association of genetic polymorphisms with a single phenotype (e.g., disease or nutritional status), but they do not consider confounding variants. The limitations of these studies include limited population size, limited number of candidate genes (1-10, e.g., MTHFR, Methylenetetrahydrofolate reductase, studies; Table 2) and/or lack of dietary/supplement intake data or status data. Here, we will discuss three diseases for which relationships with folate and folate-dependent genes have been studied: NTDs; intestinal cancers; and, cardiovascular disease.

\section{NEURAL TUBE DEFECTS}

Folate consumption and status during the peri-conceptional period has long been associated with a reduction in developmental anomalies, including NTDs (14, 40-42). During pregnancy, NTDs occur between 21 and 28 days after conception if the neural plate fails to fold properly to form the neural tube, the precursor of the spinal cord and brain. When the neural tube fails to close, numerous NTD defects can arise including spina bifida and anencephaly (43). Adequate maternal peri-conceptional folic acid supplementation significantly reduces the risk of primary or recurrent NTDs $(14,40)$. In an effort to reduce the number of NTD-affected pregnancies, many countries, including Canada and the United States, have mandated folic acid fortification of white flour and other cereal products (44-46). In Canada, NTD incidence has decreased by $\sim 45 \%$ since the start of fortification (47). The specific mechanism(s) by which folate prevents NTDs remains poorly understood, but its role in nucleotide synthesis, DNA repair and cellular methylation reactions are likely important.

The early observation of a high recurrence rate of NTDs pointed to possible genetic contributors to pathogenesis. Numerous studies have sought to identify the underlying genetic factors influencing NTD prevalence (48-52). The genetic link combined with the evident association between maternal folate status and NTDs led to the evaluation of candidate genes directly or indirectly involved in the folate metabolic pathway, including MTHFR, methionine synthase (MTR), betaine-homocysteine methyltransferase (BHMT), and serine hydroxymethyltransferase (SHMT) to 
Table 2 | Major findings from association studies between MTHFR gene variants and two proof of principle diseases, neural tube defects, and cancer risk, including sample size, significance (as $p$ or $95 \%$ confidence interval), and odds ratio (OR).

\begin{tabular}{|c|c|c|c|c|c|}
\hline Research Study & Approach & Findings & Sample Size & Significance & OR \\
\hline \multicolumn{6}{|l|}{ MTHFR AND NTDs } \\
\hline Boyles et al. (35) & $\begin{array}{l}\text { GWAS, clinical } \\
\text { sample population }\end{array}$ & $\begin{array}{l}\text { No significant MTHFR SNP (rs1801133)/NTD risk associations } \\
\text { in individuals not taking maternal folate supplements }\end{array}$ & Total: 304 & $p: 0.203$ & \\
\hline Shaw et al. (33) & $\begin{array}{l}\text { Candidate gene, } \\
\text { large sample } \\
\text { population }\end{array}$ & $\begin{array}{l}\text { Significant association between MTHFR SNP (rs1801133) and } \\
\text { NTD risk. No link between intake and allele frequency }\end{array}$ & $\begin{array}{l}\text { Cases: } 259, \\
\text { controls: } 359\end{array}$ & $\begin{array}{l}95 \% \mathrm{Cl}: \\
1.2-3.1\end{array}$ & 2.0 \\
\hline Pangilinan et al. (34) & tagSNP & $\begin{array}{l}\text { Significant association between MTHFR SNPs (rs17037425, } \\
\text { rs17367504) and NTD risk }\end{array}$ & $\begin{array}{l}\text { Cases: } 301 \\
\text { controls: } 341\end{array}$ & $\begin{array}{l}p: 0.0068 \\
p: 0.0081\end{array}$ & \\
\hline \multicolumn{6}{|c|}{ MTHFR AND CANCER RISK } \\
\hline Vollset et al. (36) & GWAS & $\begin{array}{l}\text { No correlations between gastric cancer and plasma folate, total } \\
\text { homocysteine and serum B12. Slight increase in gastric cancer } \\
\text { risk with MTHFR (rs1801133). }\end{array}$ & $\begin{array}{l}\text { Cases: } 245, \\
\text { controls: } 631\end{array}$ & $p: 0.04$ & 1.47 \\
\hline Terry et al. (38) & Candidate gene & $\begin{array}{l}\text { MTHFR SNPs (rs1801131, rs1801133) showed no significant } \\
\text { association with increased ovarian cancer risk. }\end{array}$ & $\begin{array}{l}\text { Cases: } 1642 \\
\text { controls: } 2068\end{array}$ & $p: 0.59, p: 0.58$ & \\
\hline Han et al. (39) & GWAS & $\begin{array}{l}\text { Link between MTHFR (rs1801131) and colorectal adenoma in } \\
\text { individuals with extremely low folate intake. }\end{array}$ & $\begin{array}{l}\text { Case: } 1331 \\
\text { controls: } 1501\end{array}$ & $p: 0.02$ & \\
\hline
\end{tabular}

name a few $(33,35,53)$. The most compelling observations have been made for the MTHFR C677T variant, for which TT homozygosity has been significantly associated with NTDs (54). While the cause of folate-dependent NTDs remains unknown, the TT genotype results in a thermolabile enzyme and reduced folate metabolism, which may reduce cell proliferation or cellular methylation reactions during embryonic development. Other folate metabolic gene variants including methylenetetrahydrofolate dehydrogenase 1 (MTHFD1), dihydrofolate reductase (DHFR), methionine synthase reductase $(M T R R)$, and the transcobalamin II receptor $(T C b l R)$ have been associated with NTDs using candidate gene/SNP analysis (55-57).

Candidate gene studies and GWAS to identify SNPs associated with NTD risk have yielded variable results. Three prominent studies examined possible associations between 118 folate pathway-linked SNPs and NTDs. Boyles et al. (35) found a weak association between betaine and homocysteine methyltransferase (BHMT), which also remethylates homocysteine using betaine rather than folate as the methyl donor, and NTD risk when mothers were receiving pre-conceptional folate supplements or when combined with the MTHFR (C677T) TT homozygosity. $B H M T$ 's role in NTD pathogenesis is poorly understood, but may be related to altered cellular methylation potential and gene expression. Shaw et al. (33) performed a candidate gene screen of these 118 SNPs in a Californian population, and found a modest association between spina bifida (NTD) risk and SNPs in seven genes related to folate metabolism [BHMT, MTHFD1, MTHFD2, MTHFR, MTRR, cystathionine- $\beta$-synthase (CBS), and thymidylate synthase (TYMS)]. For nearly all of these variants, (rare) allele homozygosity can result in reduced folate metabolism and its endpoints. An additional analysis of these pathways using haplotype and tagSNP screening approaches identified 68 SNPs associated with NTD risk in genes from the folate metabolic pathway, MTHFR and mitochondrial folate transporter (MFTC); DNA methylation, DNA (cytosine-5)-methyltransferase 3A (DNMT3A); $\mathrm{B}_{12}$ metabolism, Cubilin (CUBN) and choline metabolism, phosphatidylethanolamine $N$-methyltransferase (PEMT) (34).

In contrast, a number of studies have found no association with some of these same gene variants. For example, a SNP in the gene methionine synthase (MTR A2756G), in the enzyme required for folate-dependent remethylation of homocysteine, was initially shown to be significantly associated with increased risk for spina bifida in a candidate gene study (58). However, Shaw et al. (33) found no association MFTC is a component of the onecarbon transport chain for which it was hypothesized that SNP variants played a role in NTD risk by reducing folate metabolism and DNA methylation. Pangilinan et al. (34) used a tagSNP approach to assess MFTC's role in NTD development and found a minor, but non-significant link with $\operatorname{MFTC}(\mathrm{R} 117 H)$. These confounding observations and lack of a solid answer in these studies may be founded in gene-environment interactions and their sometimes subtle effect on phenotype. For example, none of these studies examined the modifying effect of nutrient intake or status on the relationship between genotypes of interest and NTD risk. The addition of dietary folate and folate status data may resolve discrepancies between studies and improve the confidence in results by providing accountability for a potentially significant environmental factor. 


\section{CANCER}

Low folate status has been associated with increased risk for numerous cancers including colon and breast cancer. This association has raised questions including: "Does compromised DNA repair lead to increased cancer risk?" "Could high dietary folate increase the rate of tumor growth?" and "What role does folate consumption or status play in individuals with low-frequency cancer pre-disposition genotypes?" Much like the studies looking at NTDs and folate-related genes, the relationship between cancer, nutrient intake, and gene variants within enzymes involved in folate and B-vitamin metabolism have relied heavily on both candidate gene studies and GWAS (Tables 3 and 4).

Recent studies have examined the association between folate status or consumption, which can be analyzed categorically or continuously, and a limited suite of SNPs in folate-related genes associated with lung, esophageal, stomach, colorectal, and kidney cancers. Examples of key genes that have been studied include MTHFR, MTHFD, MTR, MTRR, folate receptor 1 (FOLR1), and fucosyltransferase 2 (FUT2; a gene associated with vitamin $\mathrm{B}_{12}$ status; Tables 2 and 3 ). The prototype gene studied in relationship to cancer is the MTHFR gene, and in particular the C677T SNP. The gene product of MTHFR plays a key role in folate metabolism, as it produces 5-methylTHF, which is used by MTR for the production of THF and methionine. The MTHFR C677T variant results in decreased levels of serum RBC folate and elevated plasma homocysteine. Folic acid supplementation can normalize folate status and enzyme activity, but absolute folate status is lower than in those individuals with the wildtype enzyme.

Since the implementation of folic acid fortification in the United States and Canada (1996 and 1997, respectively), a slowdown in the rate of colorectal cancer (CRC) decline has been suggested to be due to high folic acid intake (65). This has raised many questions regarding the role of folate in CRC risk. Although many studies indicate that high folate status is associated with reduced CRC risk, a handful has suggested that high levels may increase CRC risk in persons with pre-cancerous legions. Liu et al. (60) examined how interactions between folate-related SNP variants and dietary intake (including folate) influence CRC risk. Individuals with DNMT $1331 \mathrm{~V}$ and low folate intake had decreased CRC risk, while higher folate intake increased CRC risk, due in part to enhanced abnormal methylation. The opposite was observed for females with MTRR (122M) homozygosity, a potential modifier of methionine metabolism. Han et al. (39) suggest that significant pathway- and gene-level associations ( $A D A$ and cysteine dioxygenase, $C D O 1$ ) exist between one-carbon metabolism genes and advanced colorectal adenoma in individuals with extremely low folate intake. These findings could point to an association between CRC risk and altered homocysteine metabolism. Alternatively, these markers may be in linkage-disequilibrium with

Table 3 | Major findings observed in association studies examining folate and vitamin $\mathrm{B}_{\mathbf{1 2}}$ metabolic pathway genes, using candidate gene studies, major diseases, and dietary folate or $\mathrm{B}_{12}$ dietary intake, including sample size, significance (as $p$ or $95 \%$ confidence interval), and risk measurement (Odds ratio, OR).

\begin{tabular}{|c|c|c|c|c|c|}
\hline Topic & Research Study & Findings & Sample Size & Significance & OR \\
\hline \multirow[t]{7}{*}{ NTD } & Doolin et al. (58) & MTR (A2756G) NTD association & Total: 209 & $95 \% \mathrm{Cl}: 0.92-5.06$ & $2.16^{\mathrm{a}}$ \\
\hline & Boyles et al. (35) & $\begin{array}{l}\text { Weak association between BHMT variants (rs3733890, } \\
\text { rs558133) in folate rich environments and NTD risk. }\end{array}$ & Total: 304 & $p: 0.027, p: 0.036$ & \\
\hline & Parle-McDermott et al. (55) & DHFR association with decreased NTD risk. & $\begin{array}{l}\text { Cases: } 283, \\
\text { controls: } 256\end{array}$ & $95 \% \mathrm{Cl}: 0.39-0.89$ & 0.59 \\
\hline & Parle-McDermott et al. (56) & MTHFD1 (rs3832406) association with increased NTD risk. & Triad n: 439 & $p: 0.002$ & \\
\hline & Shaw et al. (33) & $\begin{array}{l}\text { Modest association between NTD risk and SNPs in BHMT, } \\
\text { CBS, MTHFD1, MTHFD2, MTHFR, MTRR, and TYMS. }\end{array}$ & $\begin{array}{l}\text { Cases: } 259, \\
\text { controls: } 359\end{array}$ & p: 0.009-0.02 & \\
\hline & Pangilinan et al. (57) & $\begin{array}{l}\text { MTHFD1 R6530 (rs2236225) and MFTC (rs17803441) } \\
\text { significantly associated with increased NTD risk. }\end{array}$ & $\begin{array}{l}\text { Cases: } 301 \\
\text { controls: } 341\end{array}$ & $p: 0.0023, p: 0.0003$ & \\
\hline & Pangilinan et al. (34) & $\begin{array}{l}68 \text { SNPs associated with NTD risk including SNPs MFTC } \\
\text { (rs17803441), CDKN2A (rs3218009), ADA (rs2299686). }\end{array}$ & $\begin{array}{l}\text { Cases: } 301 \\
\text { controls: } 341\end{array}$ & $\begin{array}{l}95 \% \mathrm{Cl}: 1.23-2.08 \\
p: 0.0098, p: 0.0004 \\
p: 0.0010\end{array}$ & 1.61 \\
\hline \multirow[t]{3}{*}{ Cancer } & Flores et al. (59) & $\begin{array}{l}\text { CBS (rs2850146) and MTRR (rs3776467) SNPs may, in } \\
\text { combination with high folic acid levels, protect against lung } \\
\text { cancer. }\end{array}$ & Total: 907 & $\begin{array}{l}95 \% \mathrm{Cl}: 1.98-12.2 \\
p: 0.0006\end{array}$ & 4.9 \\
\hline & Liu et al. (60) & $\begin{array}{l}\text { DNMT } 1331 \mathrm{~V} \text { and MTRR } 122 \mathrm{M} \text { significantly interacting with } \\
\text { dietary intake to modify CRC risk. }\end{array}$ & $\begin{array}{l}\text { Cases: } 1609, \\
\text { controls: } 1974\end{array}$ & $p: 0.04, p: 0.02$ & \\
\hline & Pabalan et al. (61) & $\begin{array}{l}\text { No significant association between SHMT1 (rs1979277) or } \\
\text { folate levels and CRC risk. }\end{array}$ & $\begin{array}{l}\text { Cases: } 5043, \\
\text { controls: } 6311\end{array}$ & $p: 0.47-0.77$ & \\
\hline
\end{tabular}

${ }^{a}$ r-Value used in place of OR. 


\begin{tabular}{|c|c|c|c|c|c|}
\hline Topic & Research Study & Findings & Sample Size & Significance & OR \\
\hline NTD & Grarup et al. (62) & $\begin{array}{l}\text { Whole genome and exome sequencing associated six novel loci with serum } \mathrm{B}_{12} \\
(C D 320, T C N 2, A B C D 4, M M A A, M M A C H C) \text { or folate levels (FOLR3) with } \\
\text { cardiovascular diseases, cancers, and neurodegenerative disorders }\end{array}$ & $\begin{array}{l}\text { Folate: } 37341 \\
\mathrm{~B}_{12}: 45576\end{array}$ & $\begin{array}{l}p: 7.11 \times 10^{-100}- \\
0.0018\end{array}$ & \\
\hline \multirow[t]{4}{*}{ Cancer } & Vollset et al. (36) & $\begin{array}{l}\text { No correlations between gastric cancer and plasma folate, total homocysteine } \\
\text { and serum B12. Slight increase in gastric cancer risk with MTHFR (rs1801133) }\end{array}$ & $\begin{array}{l}\text { Cases: } 245, \\
\text { controls: } 631\end{array}$ & $p: 0.04$ & 1.47 \\
\hline & Han et al. (39) & $\begin{array}{l}\text { SNPs in ADA (rs244072), CDO1 (rs34869) and FOLR1 (rs10501409) associated } \\
\text { with advanced colorectal adenoma in individuals with extremely low folate intake }\end{array}$ & $\begin{array}{l}\text { Cases: } 1331, \\
\text { controls: } 1501\end{array}$ & $\begin{array}{l}p: 0.001 \\
p: 0.007, p: 0.008\end{array}$ & \\
\hline & Tanaka et al. (64) & $\begin{array}{l}\text { Significant associations between plasma } B_{6} \text { and ALPL (rs4654748), serum B12 } \\
\text { and FUT (rs602662), and homocysteine and MTHFR (rs1801133) }\end{array}$ & $n=2930$ & $\begin{array}{l}p: 8.30 \times 10^{-18} \\
p: \\
p: 83 \times 10^{-20} \\
p: 36 \times 10^{-13}\end{array}$ & \\
\hline & Hazra et al. (63) & $\begin{array}{l}\text { Meta-analysis of } 3 \text { GWAS confirmed or identified strong associations between } \\
\mathrm{B}_{12} \text { and FUT2 (rs602662, rs492602) and between plasma homocysteine and } \\
\text { MTHFR (rs1081133) }\end{array}$ & Total: 4763 & $\begin{array}{l}p: 1.83 \times 10^{-15} \\
p: 1.30 \times 10^{-14} \\
p: 1.27 \times 10^{-8}\end{array}$ & \\
\hline
\end{tabular}

unsampled, but relevant genes. A meta-analysis of case-control studies of the SHMT1 C1420T SNP found no significant association between gene variants or folate levels and CRC risk (61). The confounding outcomes suggest that further study of the genegene interactions are required to resolve the factors leading to pre-disposition and to identify the role of genotypic interactions on phenotypic expression. Using a larger sample-set and/or highthroughput methods may facilitate the study of these interactions at very high resolutions.

Folate-gene association studies have identified more than 100 folate pathway SNPs related to digestive system cancers. In European populations, Vollset et al. (36) found a significant association between the MTHFR (1298 A > C) SNP and increased risk of gastric cancer, potentially due to significantly altered concentrations of circulating folate and homocysteine. Using candidate gene analysis, Zhang et al. (66) indicated that MTR (Ex26_20 A > G) and MTRR $(E \times 5123 \mathrm{C}>\mathrm{T}) \mathrm{SNPs}$ are associated with a borderline increased risk of stomach cancer in the Polish population. These polymorphisms may cause increased risk by altering homocysteine to methionine conversions, subsequently increasing homocysteine levels. No significant interactions were observed between dietary folate intake and cancer risk. Though, the findings from both studies indicate that at least three SNP markers are associated with digestive system cancers, their small sample size and regional location may lead to population stratification artifacts, restricting how the results can be extrapolated.

Ibiebele et al. (37) found that nutrient intake played a more important role than gene variants in esophageal cancer risk. Adequate folate intake reduced overall cancer risk, but supplemental folic acid and vitamin $\mathrm{B}_{12}$ was significantly associated with increased Barrett's esophagus and esophageal adenocarcinomas (37). No significant associations were observed between SNPs from the MTHFR, MTRR, and MTR genes and cancer risk, regardless of dietary intake, suggesting that diet may be the critical factor in increasing the risks of these cancers.
Other studies have attempted to link folate metabolic pathway genes with non-digestive tract cancers. Hu et al. (67) performed a meta-analysis and determined that the MTRR A66G SNP was not associated with breast cancer risk. A candidate gene study of the MTHFR SNPs C677T and A1298C showed no significant association with increased ovarian cancer risk in a case-control study of American women (38). Flores et al. (59) determined, using a candidate gene SNP study, that SNPs in CBS $(8283 G>C)$ and MTRR (7068 $A>G$ ) have sex-specific associations with aberrant methylation in the lung epithelium of smokers that could be mediated by their effects on one-carbon metabolism and transsulfuration. It was proposed that in rare cases these variations could act, in combination with high folic acid levels, to protect against lung cancer (68). All of these findings highlight the complex interaction of dietary folate, vitamin $\mathrm{B}_{12}$, and homocysteine with genotypic variation.

\section{CARDIOVASCULAR DISEASE}

The link between low intake and status of folate, B-vitamins, high circulating homocysteine, and cardiovascular diseases, including coronary heart disease and stroke has long been a topic of interest (Table 4). The early findings of non-genomic studies suggested that high homocysteine levels in the blood (hyperhomocysteinemia) were weakly correlated to increased risk of cardiovascular disease (69). This has led to the hypothesis that folic acid and B-vitamin supplementation could reduce the risk of cardiovascular disease by lowering homocysteine concentrations. Building on these observations, various candidate gene and GWAS's were conducted to determine the genetic underpinnings of folate-related cardiovascular disease. The focus of many of these studies was the relationship between genotype and B-vitamin status, homocysteine levels, and cardiovascular disease. Early candidate gene studies found moderate risk associations between high homocysteine and MTHFR C667T homozygosity, which would ultimately cause an additional increase in homocysteine, and potentially contribute 
to increased risk for atherosclerosis and blood clot formation. (70). Tanaka et al. (64) found associations between plasma $\mathrm{B}_{6}$ level and ALPL (rs4654748 C > T: a component in $\mathrm{B}_{6}$ catabolism), plasma $\mathrm{B}_{12}$ levels and $F U T$ (rs602662 A $>$ G: reduces $\mathrm{B}_{12}$ absorption), and homocysteine levels and MTHFR C667T. This highlighted potential connections between these metabolic pathways. However, two meta-analyses found no significant correlations between homocysteine, the MTHFR C677T SNP, and cardiovascular risks (69, 71). The association between ALPL and MTHFR SNPs and homocysteine, combined with homocysteine's role in CVD risk, suggest that these markers may be suitable predictors of plasma homocysteine and also potentially CVD. Expanding the size of study populations combined with new analytical approaches, including continuous trait associations, may improve our ability to identify SNPs that are suitable biomarkers for cardiovascular disease.

\section{CAN SNPS ASSOCIATED WITH FOLATE AND B-VITAMIN STATUS AND THEIR ASSOCIATED DISEASES PREDICT FOLATE STATUS?}

Our on-going work aims to tease apart the contributions of diet and genetics on folate status and associated disease risk. Only one past study (Table 3) has examined these interactions with regards to folate using a single-marker. The MTHFR C677T SNP was shown to reduce folate status and is associated with NTDs and cancer, the risk of which can be mitigated by increased folate intake. We are performing a moderately high-throughput analysis to elucidate similar relationships between a panel of $\sim 120$ folaterelated SNPs and folate status and their modification by dietary folate intake. The predictive power of key SNPs identified from previous candidate gene and GWAS analyses will allow us to estimate proportions of the population that may be most impacted by folic acid intake from food fortification and supplement use. This could include identifying groups that derive particular benefit from the consumption of additional folic acid as well as those individuals that may be at risk for over-exposure. Consideration of folate intake may also reduce the ambiguity of results from previous studies that did not control for this obvious confounding variable.

We have designed a two step analysis to address this issue using DNA samples from the Canadian Health Measure Survey, cycle 1 with a samples size of approximately 3200 adults aged 20 years and older. Information on the participants' folate and vitamin B12 dietary intake and supplementation was collected, and red blood cell folate, serum vitamin B12, and plasma total homocysteine were measured. The first step of our analysis will examine the association between candidate SNPs, which were previously associated with nutrient status or disease, and the phenotypic variables red blood cell folate, plasma vitamin $\mathrm{B}_{12}$, and plasma total homocysteine using single-marker and multi-marker (haplotype and gene-gene interaction) approaches. The multi-marker analysis may reveal multi-gene interactions that influence an individual's nutrient status. The analysis will be expanded in the second step with the addition of the environmental variables, including dietary, and supplement intake of the nutrients, to identify SNPs that modify the expected relationship between nutrient intake and status. Ultimately, we hope to refine our understanding of the relationship between these SNPs and nutrient status by controlling for nutrient intake, as well as identifying SNPs that may result in hypoor hyper-responsiveness to nutrient intake (e.g., SNPs that result in lower or higher than expected status).

The data from studies such as we are performing will help to inform, update, and refine policies, regulations, and recommendations to maximize the benefits of folic acid while minimizing the risks of over-exposure to genetically susceptible sub-populations. The general approach, we are proposing can be applied to other nutrients and environmental factors to begin to understand the implications of food policies and regulations for individuals in the general population. The ultimate goal of public health policy is to improve the quality of life and health for the majority of a given population. Improved understanding of the relationship between nutrient intake, genetic variation, and nutrient status or disease may therefore allow for the refinement of nutrition policies.

\section{ACKNOWLEDGMENTS}

This work was supported by Health Canada (Amanda J. MacFarlane) and a Genomics Research and Development Initiative grant from the Public Health Agency of Canada (Amanda J. MacFarlane). John W. R. Zinck is the recipient of a Visiting Fellowship in Canadian Government Laboratories Program by the Natural Sciences and Engineering Research Council of Canada. We thank Alex Wong for critical revision of the manuscript.

\section{REFERENCES}

1. Tremblay M, Wolfson M, Connor GS. Canadian Health Measures Survey: rationale, background and overview. Health Reports (2007) 18(Suppl):7-20.

2. Sachidanandam R, Weissman D, Schmidt SC, Kakol JM, Stein LD, Marth G. A map of human genome sequence variation containing 1.42 million single nucleotide polymorphisms. Nature (2001) 409:928-33. doi:10.1038/35057149

3. Venter JC, Adams MD, Myers EW, Li PW, Mural RJ, Sutton GG. The sequence of the human genome. Science (2001) 291:1304-51. doi:10.1126/science.1058040

4. Kong A, Gudbjartsson DF, Sainz J, Jonsdottir GM, Gudjonsson SA, Richardsson $\mathrm{B}$, et al. A high-resolution recombination map of the human genome. Nat Genet (2002) 31:241-7. doi:10.1038/ng917

5. Grody WW. Molecular genetic risk screening. Annu Rev Med (2003) 54:473-90. doi:10.1146/annurev.med.54.101601.152127

6. Willett WC. Balancing lifestyle and genomic research for disease prevention. Science (2002) 5568:695-8. doi:10.1126/science.1071055

7. Ottman R. An epidemiological approach to gene-environment interaction. Genet Epidemiol (1990) 7:177-85. doi:10.1002/gepi.1370070302

8. Hunter DJ. Gene-environment interactions in human diseases. Nat Rev (2005) 6:287-98. doi:10.1038/nrg1578

9. Manolio TA, Bailey-Wilson JE, Collins FS. Genes, environment and the value of prospective cohort studies. Nat Rev Genet (2006) 7:812-20. doi:10.1038/nrg1919

10. Wolffe AP, Matzke MA. Epigenetics: Regulation through repression. Science. (1999) 5439:481-6. doi:10.1126/science.286.5439.481

11. Soto-Ramírez N, Arshad SH, Holloway J, Zhang H, Schauberger E, Ewart S, et al. The interaction of genetic variants and DNA methylation of the interleukin-4 receptor gene increase the risk of asthma at age 18 years. Clin Epigenet (2013) 1:1. doi:10.1186/1868-7083-5-1

12. Willett WC. Vitamin A and lung cancer. Nutr Rev (1990) 48201:211.

13. Martorell R. Undernutrition during pregnancy and early childhood and its consequences for cognitive and behavioral development. In: Young ME, editor. Early Childhood Development: Investing in Our Children's Future. Amsterdam: Elsevier (1997).

14. Czeizel AE, Dudás I. Prevention of the first occurrence of neural-tube defects by periconceptional vitamin supplementation. N Engl J Med (1992) 26:1832-5. doi:10.1056/NEJM199212243272602

15. Kaput J, Rodriguez RL. Nutritional genomics: the next frontier in the post genomicera. Physiol Genomics (2004) 16:166-77. doi:10.1152/physiolgenomics. 00107.2003 
16. Kaput J. Nutrigenomics research for personalized nutrition and medicine. Curr Opin Biotechnol. (2008) 2:110-20. doi:10.1016/j.copbio.2008.02.005

17. Kwon JM, Goate AM. The candidate gene approach. Alcohol Res Health. (2000) 3:164-8.

18. Tabor HK, Risch NJ, Myers RM. Candidate gene approaches for studying complex genetic traits: practical considerations. Nat Rev Genet (2002) 5:391-7. doi: $10.1038 / \mathrm{nrg} 796$

19. Houlston RS, Tomlinson IP. Polymorphisms and colorectal tumor risk. Gastroenterology (2001) 121:282-301. doi:10.1053/gast.2001.26265

20. Tomlinson I. Colorectal cancer genetics: from candidate genes to GWAS and back again. Mutagenesis (2012) 27:141-2. doi:10.1093/mutage/ger072

21. Manolio TA. Genome-wide association studies and assessment of the risk of disease. N Engl J Med (2010) 363:166-76. doi:10.1056/NEJMra0905980

22. Stahl EA, Raychaudhuri S, Remmers EF, Xie G, Eyre S. Genome-wide association study meta-analysis identifies seven new rheumatoid arthritis risk loci. Nat Genet (2010) 42:508-14. doi:10.1038/ng.582

23. Terwilliger JD, Weiss KM. Linkage disequilibrium mapping of complex disease: fantasy or reality? Curr Opin Biotechnol (1998) 9:578-94. doi:10.1016/S09581669(98)80135-3

24. Bodmer W, Bonilla C. Common and rare variants in multifactorial susceptibility to common diseases. Nat Genet (2008) 40:695-701. doi:10.1038/ng.f.136

25. Gyenesei A, Moody J, Semple CA, Haley CS, Wei WH. High-throughput analysis of epistasis in genome-wide association studies with BiForce. Bioinformatics (2012) 15:1957-64. doi:10.1093/bioinformatics/bts304

26. Jia P, Wang L, Fanous AH, Pato CN, Edwards TL, Zhao Z. Network-assisted investigation of combined causal signals from genome-wide association studies in schizophrenia. PLoS Comput Biol (2012) 7:e1002587. doi:10.1371/journal. pcbi. 1002587

27. Marttinen P, Gillberg J, Havulinna A, Corander J, Kaski S. Genome-wide association studies with high-dimensional phenotypes. Stat Appl Genet Mol (2013) 4:413-31. doi:10.1515/sagmb-2012-0032

28. Van den Oord EJ, Sullivan PF. False discoveries and models for gene discovery. Trends Genet (2003) 10:537-42. doi:10.1016/j.tig.2003.08.003

29. Fox JT, Stover PJ. Folate-mediated one-carbon metabolism. Vitam Horm (2008) 79:1-44. doi:10.1016/S0083-6729(08)00401-9

30. Duthie SJ, Hawdon A. DNA instability (strand breakage, uracil misincorporation, and defective repair). is increased by folic acid depletion in human lymphocytes in vitro. FASEB J (1998) 12(14):1491-7.

31. Wei Q, Shen H, Wang LE, Duphorne CM, Pillow PC, Guo Z, et al. Association between low dietary folate intake and suboptimal cellular DNA repair capacity. Cancer Epidemiol Biomarkers Prev (2003) 12:963-9.

32. MacFarlane AJ, Greene-Finestone LS, Shi Y. Vitamin B-12 and homocysteine status in a folate-replete population: results from the Canadian Health Measures Survey. Am J Clin Nutr (2011) 4:1079-87. doi:10.3945/ajcn.111.020230

33. Shaw GM, Lu W, Zhu H. 118 SNPs of folate-related genes and risks of spina bifida and conotruncal heart defects. BMC Med Genet (2009) 10:49. doi:10.1186/1471-2350-10-49

34. Pangilinan F, Molloy AM, Mills JL, Troendle JF, Parle-McDermott A, Signore C, et al. Evaluation of common genetic variants in 82 candidate genes as risk factors for neural tube defects. BMC Med Genet (2012) 13:62. doi:10.1186/1471-235013-62

35. Boyles AL, Billups AV, Deak KL. Neural tube defects and folate pathway genes: family-based association tests of gene-gene and gene-environment interactions. Environ Health Perspect (2006) 10:1547-52. doi:10.1289/ehp.9166

36. Vollset SE, Igland J, Jenab M, Fredriksen A, Meyer K, Eussen S, et al. The association of gastric cancer risk with plasma folate, cobalamin, and methylenetetrahydrofolate reductase polymorphisms in the European Prospective Investigation into Cancer and Nutrition. Cancer Epidemiol Biomarkers Prev (2007) 11:2416-24. doi:10.1158/1055-9965.EPI-07-0256

37. Ibiebele TI, Hughes MC, Pandeya N, Zhao Z, Montgomery G, Hayward N, et al. High intake of folate from food sources is associated with reduced risk of esophageal cancer in an Australian population. J Nutr (2011) 141:274-83. doi:10.3945/jn.110.131235

38. Terry KL, Tworoger SS, Goode EL, Gates MA, Titus-Ernstoff L, Kelemen LE, et al. MTHFR polymorphisms in relation to ovarian cancer risk. Gynecol Oncol (2010) 2:319-24. doi:10.1016/j.ygyno.2010.08.007

39. Han SS, Sue LY, Berndt SI, Selhub J, Burdette LA, Rosenberg PS, et al. Associations between genes in the one-carbon metabolism pathway and advanced colorectal adenoma risk in individuals with low folate intake. Cancer Epidemiol Biomarkers Prev (2012) 21:417-27. doi:10.1158/1055-9965.EPI-11-0782

40. MRC Vitamin Study Research Group. Prevention of neural tube defects: results of the Medical Research Council Vitamin Study. Lancet (1991) 338:131. doi:10.1016/0140-6736(91)90133-A

41. Seller MJ. Multi-site neural tube closure in humans and maternal folate supplementation. Am J Med Genet (1995) 58:222-4. doi:10.1002/ajmg.1320580305

42. van der Put NM, van Straaten HW, Trijbels FJ, Blom HJ. Folate, homocysteine and neural tube defects: an overview. Exper Biol Med (2001) 226:243-70.

43. Botto LD, Moore CA, Khoury MJ. Neural tube defects. N Engl J Med (1999) 341:1509-19. doi:10.1056/NEJM199911113412006

44. Podolsky DK. The current future understanding of inflammatory bowel disease. Bailliere Best Pract Res Clin Gastroenterol (2002) 6:933-43. doi:10.1053/ bega. 2002.0354

45. Podolsky DK. Inflammatory bowel disease. N Engl J Med. (2002) 6:417-29. doi:10.1056/NEJMra020831

46. Hussain SP, Hofseth LJ, Harris CC. Radical causes of cancer. Nat Rev Cancer (2003) 4:276-85. doi:10.1038/nrc1046

47. De Wals P, Tairou F, Van Allen MI, Uh SH, Lowry RB, Sibbald B, et al. Reduction in neural-tube defects after folic acid fortification in Canada. $N$ Engl J Med (2007) 2:135-42. doi:10.1056/NEJMoa067103

48. Christensen B, Arbour L, Tran P, Leclerc D, Sabbaghian N, Platt R, et al. Genetic polymorphisms in methylene tetrahydrofolate reductase and methionine synthase, folate levels in red blood cells, and risk of neural tube defects. Am J Med Genet (1999) 84:151-7. doi:10.1002/(SICI)1096-8628(19990521)84: 2<151::AID-AJMG12>3.3.CO;2-K

49. Botto LD, Yang QH. 5,10-Methylenetetrahydrofolate reductase gene variations and congenital anomalies: a huge review. Am J Epidemiol (2000) 151:862-77. doi:10.1093/oxfordjournals.aje.a010290

50. Finnell R, Gould A, Spiegelstein O. Pathobiology and genetics of neural tube defects. Epilepsia (2003) 44(Suppl 3):14-23. doi:10.1046/j.1528-1157.44.s3.5.x

51. Greene ND, Stanier P, Copp AJ. Genetics of human neural tube defects. Hum Mol Gen. (2009) 18:113-29. doi:10.1093/hmg/ddp347

52. Yan L, Zhao L, Long Y, Zou P, Ji G, Aihua G, et al. Association of the maternal MTHFR C677T polymorphism with susceptibility to neural tube defects in offsprings: evidence from case-control studies. PLOS One. (2012) 10:e41689. doi:10.1371/journal.pone.0041689

53. Martinez CA, Northrup H, Lin JI. Genetic association study of putative functional single nucleotide polymorphisms of genes in folate metabolism and spina bifida. Am J Obstet Gynecol. (2009) 4:394. doi:10.1016/j.ajog.2009.06.042

54. Botto LD, Lynberg MC, Erickson JD. Congenital heart defects, maternal febrile illness, and multivitamin use? A population-based study. Epidemiology (2001) 12:485-90. doi:10.1097/00001648-200109000-00004

55. Parle-McDermott A, Pangilinan F, Mills JL, Kirke PN, Gibney ER, Troendle J, et al. The 19bp deletion polymorphism in intron-1 of dihydrofolate reductase (DHFR). may protect against Spina Bifida risk by increasing gene expression. Am J Med Genet. (2007) 11:1174-80. doi:10.1002/ajmg.a.31725

56. Parle-McDermott A, Pangilinan F, O’Brien KK, Mills JL, Magee AM, Troendle J, et al. A common variant in MTHFD1L is associated with neural tube defects and mRNA splicing efficiency. Hum Mutat (2009) 12:1650-6. doi:10.1002/humu. 21109

57. Pangilinan F, Mitchell A, VanderMeer J, Molloy AM, Troendle J, Conley M, et al. Transcobalamin II receptor polymorphisms are associated with increased risk for neural tube defects. J Med Genet (2010) 10:677-85. doi:10.1136/jmg.2009. 073775

58. Doolin MT, Barbaux S, McDonnell M, Hoess K, Whitehead AS, Mitchell LE Maternal genetic effects, exerted by genes involved in homocysteine remethylation, influence the risk of spina bifida. Am J Hum Genet (2002) 5:1222-6. doi:10.1086/344209

59. Flores KG, Stidley CA, Mackey AJ, Picchi MA, Stabler SP, Siegfried JM, et al. Sex-specific association of sequence variants in CBS and MTRR with risk for promoter hypermethylation in the lung epithelium of smokers. Carcinogenesis (2012) 8:1542-7. doi:10.1093/carcin/bgs194

60. Liu AY, Scherer D, Poole E, Potter JD, Curtin K, Makar K, et al. Gene-dietinteractions in folate-mediated one-carbon metabolism modify colon cancer risk. Mol Nutr Food Res (2013) 4:721-34. doi:10.1002/mnfr.201200180

61. Pabalan N, Jarjanazi H, Ozcelik H. A meta-analysis of the C1420T polymorphism in cytosolic serine hydroxmethyltransferase (SHMT1) among caucasian 
colorectal cancer populations. Int J Colorectal Dis (2013) 28:925-32. doi:10. 1007/s00384-013-1639-3

62. Grarup N, Sulem P, Sandholt CH, Thorleiffsson G, Ahluwalia TS, Sterinthorsdottir V, et al. Genetic architecture of vitamin B12 and folate levels uncovered applying deeply sequenced large datasets. PLoS Genet (2013) 6:e1003530. doi:10.1371/journal.pgen.1003530

63. Hazra A, Kraft P, Lazarus R, Chen C, Chanock SJ, Jaques P, et al. Genome-wide significant predictors of metabolites in the one-carbon metabolism pathway. Hum Mol Genet (2009) 23:4677-87. doi:10.1093/hmg/ddp428

64. Tanaka T, Scheet P, Giusti B, Bandinelli S, Piras MG, Usala G, et al. Genomewide association study of vitamin B6, vitamin B12, folate, and homocysteine blood concentrations. Am J Hum Genet (2009) 84:477-82. doi:10.1016/j.ajhg. 2009.02.011

65. Mason JB, Dickstein A, Jacques PF, Haggarty P, Selhub J, Dallal G, et al. A temporal association between folic acid fortification and an increase in colorectal cancer rates may be illuminating important biological principles: a hypothesis. Cancer Epidemiol Biomarkers Prev (2007) 16:1325-9. doi:10.1158/1055-9965. EPI-07-0329

66. Zhang FF, Terry MB, Ho L, Chen J, Lissowska J. Genetic polymorphisms in folate metabolism and the risk of stomach cancer. Cancer Epidemiol Biomarkers Prev (2007) 16:115-21. doi:10.1158/1055-9965.EPI-06-0513

67. Hu J, Zhou GW, Wang N, Wang YJ. MTRR A66G polymorphisms and breast cancer risk: a meta-analysis. Breast Cancer Res Treat (2010) 3:779-84. doi:10.1007/s10549-010-0892-1

68. Johansson M, Relton C, Ueland PM, Vollset SE, Midttun O, Nygård O, et al. Serum B vitamin levels and risk of lung cancer. JAMA (2010) 303:2377-85. doi:10.1001/jama.2010.808

69. Clarke R, Halsey J, Lewington S, Lonn E, Armitage J, Manson JE, et al. Effects of lowering homocysteine levels with B vitamins on cardiovascular disease, cancer, and cause-specific mortality: meta-analysis of 8 randomized trials involving 37485 individuals. Arch Intern Med (2010) 18:1622-31. doi:10.1001/ archinternmed.2010.348

70. Klerk M, Verhoef P, Clarke R, Blom HJ, Kok FJ, Schouten EG. MTHFR Studies Collaboration Group. MTHFR $677 \mathrm{C}>\mathrm{T}$ polymorphism and risk of coronary heart disease: a meta-analysis. JAMA (2002) 288:2023-31. doi:10.1001/jama. 288.16.2023

71. Clarke R, Bennett DA, Parish S, Verhoef P, Dötsch-Klerk M, Lathrop M, et al. Homocysteine and coronary heart disease: meta-analysis of MTHFR case-control studies, avoiding publication bias. PLoS Med (2012) 2:e1001177. doi:10.1371/journal.pmed.1001177

Conflict of Interest Statement: The authors declare that the research was conducted in the absence of any commercial or financial relationships that could be construed as a potential conflict of interest.

Received: 02 April 2014; accepted: 25 June 2014; published online: 14 July 2014.

Citation: Zinck JWR and MacFarlane AJ (2014) Approaches for the identification of genetic modifiers of nutrient dependent phenotypes: examples from folate. Front. Nutr. 1:8. doi: 10.3389/fnut.2014.00008

This article was submitted to Nutrigenomics, a section of the journal Frontiers in Nutrition.

Copyright $\odot 2014$ Zinck and MacFarlane. This is an open-access article distributed under the terms of the Creative Commons Attribution License (CC BY). The use, distribution or reproduction in other forums is permitted, provided the original author(s) or licensor are credited and that the original publication in this journal is cited, in accordance with accepted academic practice. No use, distribution or reproduction is permitted which does not comply with these terms. 